\title{
Evaluation of Factors Related to Postoperative Complications in Patients Who Underwent Reduction Mammoplasty
}

(1) Gaye Toplu, (1) Dinçer Altınel, (1) Merdan Serin

Department of Plastic Surgery, University of Health Sciences Turkey, İstanbul Training and Research Hospital, İstanbul, Turkey

\begin{abstract}
Objective: This study aimed to investigate whether there was an increase in the number of postoperative complications in patients undergoing reduction mammoplasty depending on the technique used (i.e., pedicle type, skin incision pattern), existence of concomitant diseases, and presence of other risk factors.

Materials and Methods: A total of 186 patients who underwent breast reduction between 2013 and 2018 (bilateral, $\mathrm{n}=170 ;$ unilateral, $\mathrm{n}=16$ ) were included in the study. A retrospective review of the data of patients who underwent reduction mammoplasty, which was performed by the same surgical team in a single institution over a 6-year period, was carried out. Superomedial, superior, and inferior pedicles were used in 99, 55, and 32 patients, respectively. The median follow-up period was 4 years.

Results: The median patient age was 45 (range: 16-75) years. The median total reduction weight was 2,194 (range: 80-4,800) grams. The median distance between the sternal notch and nipple was $31 \mathrm{~cm}$ (range: $24-45 \mathrm{~cm}$ ) for the right breast and $30 \mathrm{~cm}$ (range: $22-45 \mathrm{~cm}$ ) for the left breast. The overall complication rate was $6.9 \%$. The complication rates in patients with and without any concomitant diseases were $10.2 \%$ and $4.6 \%$, respectively. The overall complication rate was significantly higher in patients with smoking habit, accessory breasts, progesterone use, cerebrovascular disease, morbid obesity (Body Mass Index $\geq 40 \mathrm{~kg} / \mathrm{m}^{2}$ ), and thalassemia.

Conclusion: Our analysis shows that the presence of concomitant diseases increases the risk for postoperative complications in patients who underwent reduction mammoplasty. Our findings do not suggest that any of the techniques have significant superiority to each other in terms of pedicle safety and overall complication rate.
\end{abstract}

Keywords: Breast reduction, superomedial pedicle, superior pedicle; inferior pedicle

Cite this article as: Toplu G, Altınel D, Serin M. Evaluation of Factors Related to Postoperative Complications in Patients Who Underwent Reduction Mammoplasty. Eur J Breast Health 2021; 17(2): 157-164

\section{Key Points}

- Our analysis shows that the presence of concomitant diseases increases the risk for postoperative complications in patients who underwent reduction mammoplasty.

- Our findings do not suggest that any of the techniques are superior to each other in terms of pedicle safety and risk of overall complications.

- No correlation was found between complications and high blood pressure, excessive breast reduction weights, and long sternal notch-nipple-areola complex distance.

\section{Introduction}

Although the main purpose of breast reduction is to reduce weight and volume of the breast, the aesthetic result is equally important. Excellent methods have been identified, and interest has shifted toward technical advancements that provide improved as well as reliable aesthetic results. At the same time, great importance is devoted to the protection of sensory and physiological functions.

Women want to reduce their breasts for both physical and psychological reasons. Heavy, saggy breasts; neck, back, waist, shoulder, and arm pain; and scars on the shoulders due to the compression of bra straps are among their complaints. As pain may become chronic, it may be at risk to maceration and dermatoses in subcutaneous areas. From a psychological aspect, very large breasts could be a focus of serious distress for young women as well as young girls. In unilateral asymmetric hypertrophy, this distress increases further (1). 
Various studies have demonstrated the role of reduction mammoplasty in reducing physical symptoms and increasing quality of life (2-9). Reduction mammoplasty has not only been shown to help resolve these physical symptoms and functional limitations in women, but has also been shown to significantly improve self-confidence and reduce emotional anxiety and depression (10-13). Recent research has shown an improvement in weight loss, exercise/physical activity levels, and even eating behaviors of patients (14). Given these benefits, many women choose to undergo reduction mammoplasty. According to the American Society of Plastic Surgeons, 129,937 breast reductions were performed in 2017 . This was done with a number of techniques, involving various pedicles, and skin resection designs.

Studies have shown that the inferior pedicle is the technique preferred by most American plastic surgeons (69\%) because it provides vascular reliability (15). However, the superomedial pedicle (SMP) technique is a reliable vascular pedicle method and an important alternative approach for reduction mammoplasty. Studies have also shown that SMP reduction mammoplasty technique is a safe and effective reduction method in cases of mild and moderate hypertrophy.

The superior pedicle technique was first described by Arie in 1957, who found it unreliable because nipple viability is compromised for long pedicle reconstructions (16). This technique was further refined by the inclusion of the medial parenchyma in 1975 by Orlando and Guthrie. They included a medical pedicle that would better provide nippleareola complex (NAC) vascularity (17). Subsequent studies using this approach have demonstrated its safety in larger breast reductions, and its complication rate was equivalent to that of the inferior pedicle technique. Comparative studies have also demonstrated reduced operative time, better cosmetic durability (less sagging or pseudoptosis over time), and fuller superior and medial appearance (beautiful décolleté) with the SMP technique $(18,19)$.

In this study, we aimed to present the long-term results of our patients who underwent breast reduction and investigate whether there was an increase in the number of complications in patients undergoing reduction mammoplasty based on the technique used (i.e., pedicle type, skin incision pattern), existence of concomitant diseases, and presence of other risk factors.

\section{Materials and Methods}

A total of 186 reduction mammoplasties performed between 2013 and 2018 , which were carried out by the same surgical team in a single institution for a 6-year period, were included in this retrospective study. Patient demographic characteristics, preoperative breast measurements, and perioperative data were analyzed. A literature review regarding the complication rates of breast reduction surgery was also performed.

Of the 186 patients with symptomatic breast enlargement, 170 had undergone bilateral and 16 had unilateral reduction mammoplasties. Patients were assessed visually and by the measurement of nipple midclavicular point before surgery, and the procedures were performed by the same team. The superomedial, superior, and inferior pedicles were used in 99, 55, and 32 patients, respectively. The median patient age was 45 (range: 16-75) years. Data were analyzed retrospectively over a 6-year period. The study population was composed of all women aged 16-75 years who had undergone bilateral and unilateral reduction mammoplasty for symptomatic macromastia. The average

\section{Surgical technique}

Markings were made while the patient was standing. The midsternal point, inframammary fold, and meridians of the breasts were marked as a line extending from the nipple to the midclavicular point. A line tangent to the most inferior point of the fold is drawn. The projection of the line was carried to the front of the breast, and the new nipple position was marked on the front of the breast at the level of the inframammary fold. For patients planned to have an inverted $t$ scar pattern, a Wise pattern was drawn with arms of $5-6 \mathrm{~cm}$ in length. These lines are further extended medially and laterally until they intersect with the inframammary fold. For patients planned to have a vertical scar, a keyhole pattern is drawn to accommodate the vertical scar.

The pedicle was designed to have an average width of $8-10 \mathrm{~cm}$ at the base. The skin over the pedicle except the nipple and areola was deepithelialized. A dermoglandular excision was performed, and the NAC was transposed into its new location. A thin breast tissue on the muscular structures was preserved in favor of the sensory innervation of the NAC. Medial and lateral pillar sutures were placed, and layered closure of skin incisions was performed. Drains were placed at the end of the surgery.

The three reduction techniques used in breast reduction have not been approached with any bias, and we have successfully applied all of them. Following the measurement of the distance between the sternal notch $(\mathrm{Sn})$ and the NAC (Sn-NAC), we also considered patient's age, height, and comorbidities to decide on the pedicle type. An Sn-NAC distance of $>38 \mathrm{~cm}$ was usually considered for the inferior pedicle rather than for the SMP. We were inclined to prefer the inferior pedicle and SMP in certain age group (such as $>60$ years old) instead of the superior pedicle. Although there were no sharp boundaries, we usually chose those who are over $1.65 \mathrm{~m}$ in height to be taller than the average population and preferred superomedial and superior pedicle in this group. Comorbidities such as diabetes, smoking, wound healing problems, and other systemic diseases were considered for the pedicle selection.

The SMP technique was the most preferred method because of its versatility and speed, both with the inverted $t$ and vertical scar pattern. In this technique, the most high-risk area of surgery is the circulation of the lateral skin flap. This flap was not left too thin or traumatized during dissection. The technique was easy to teach and apply. This pedicle can be combined with the vertical scar technique. The dissection of the pedicle is almost the same with the vertical technique; the only difference is that at the end of the operation, the skin is made suitable for the breast and excess skin is removed by combining it with vertical technique or a short $\mathrm{t}$ scar (1).

\section{Statistical analysis}

Chi-square test and descriptive analysis were performed using the GraphPad Prism 7.0 software (GraphPad Software, Inc., La Jolla, CA, USA). Difference with a p-value of $<0.05$ was considered significant.

\section{Results}

The inverted t/Wise pattern incision was used in 171 patients, followed by the vertical pattern incision in 15 patients. The median age was 45 (range: 16-75) years, and the median Body Mass Index (BMI) was 29 (range: $22-41$ ) $\mathrm{kg} / \mathrm{m}^{2}$. Eight patients had a history of breast cancer. Patient morbidities included high blood pressure $(\mathrm{n}=$ $21)$, diabetes $(n=11)$, psychiatric problems $(n=6)$, asthma $(n=3)$, tobacco use $(n=8)$, and drug use $(n=2)$ (Tables 1-2, Figures 1-4). 


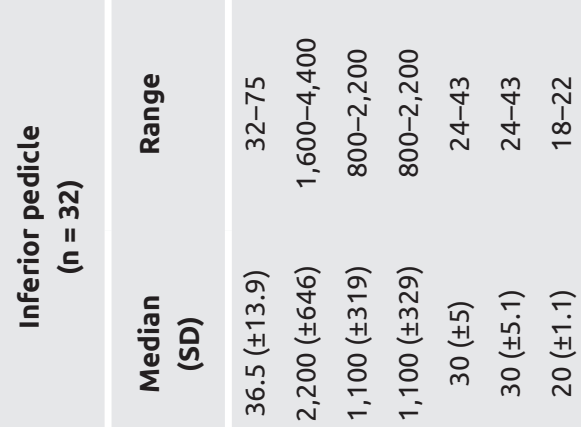

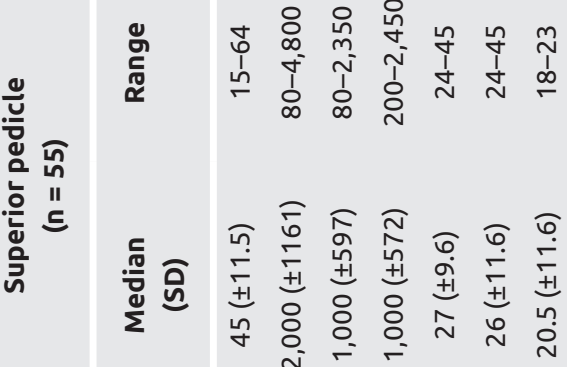

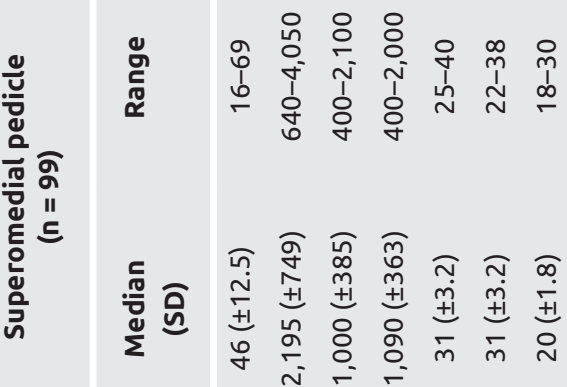

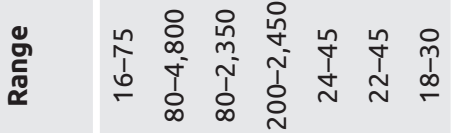

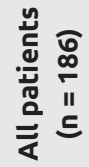

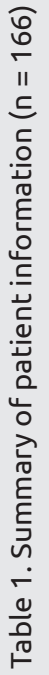

\section{SMP}

The median total reduction weight, median right breast reduction weight, and median left breast reduction weight were 2,195 (range: 640-4,050) grams, 1,100 (range: 400-2,100) grams, and 1,090 (range: 400-2,000) grams, respectively. The median preoperative SNnipple distance was $31 \mathrm{~cm}(25-40 \mathrm{~cm})$ for the right breast and 31 $\mathrm{cm}$ (range: $22-38 \mathrm{~cm}$ ) for the left breast. The median postoperative SN-nipple distance was $20 \mathrm{~cm}$ (range: $18-30 \mathrm{~cm}$ ) for both breasts (Table 1).

\section{Superior pedicle}

The median total reduction weight, median right breast reduction weight, and median left breast reduction weight were 2,000 (range: 80-4,800) grams, 1,000 (range: 80-2,350) grams, and 1,000 (range: 200-2,450) grams, respectively. The median preoperative SN-nipple

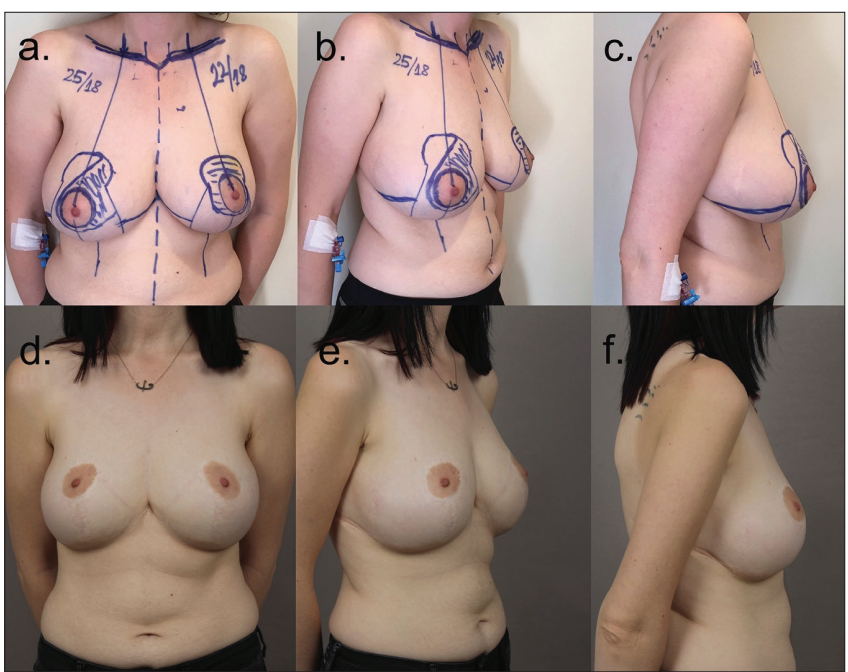

Figure 1. Preoperative frontal (a), oblique (b), and lateral (c) views of a patient. Five-year postoperative frontal (a), oblique (b), and lateral (c) views of the patient following breast reduction with the superomedial pedicle

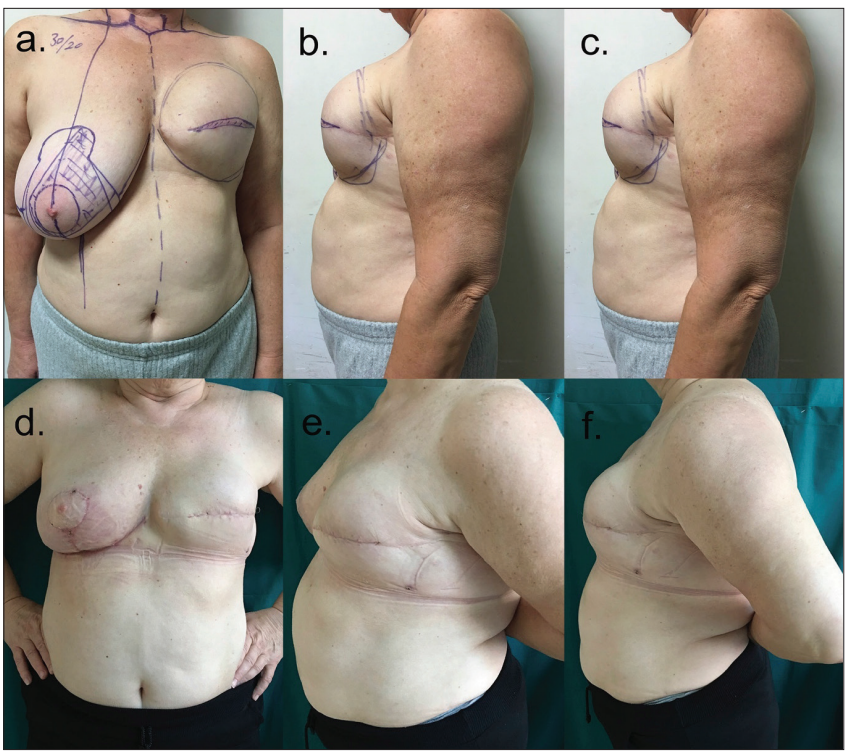

Figure 2. Preoperative frontal (a), oblique (b), and lateral (c) preoperative views of a patient. Three-year postoperative frontal (a), oblique (b), and lateral (c) views of the patient following unilateral breast reduction with the superomedial pedicle 
Table 2. Concomitant diseases and conditions

\begin{tabular}{|c|c|c|c|c|c|c|}
\hline & Superomedial & Superior & Inferior & Total & Complication rate & p-value \\
\hline High blood pressure & 14 & 6 & 1 & 21 & $1(4.7 \%)$ & 0.67 \\
\hline Diabetes mellitus & 6 & 5 & - & 11 & $1(9 \%)$ & 0.77 \\
\hline Smoking & 8 & - & - & 8 & $2(25 \%)$ & $0.04(*)$ \\
\hline Breast cancer & 2 & 6 & - & 8 & - & 0.42 \\
\hline Psychiatric conditions & 6 & - & - & 6 & - & 0.49 \\
\hline Asthma & 1 & 2 & - & 3 & - & 0.63 \\
\hline Accessory breast & 2 & - & - & 2 & $1(50 \%)$ & $0.01\left(^{*}\right)$ \\
\hline Progesterone use & 1 & - & 1 & 2 & $1(50 \%)$ & $\left.0.01{ }^{*}\right)$ \\
\hline Hyperthyroidism & 1 & - & 1 & 2 & - & 0.69 \\
\hline Arrhythmia & 1 & - & - & 1 & - & 0.78 \\
\hline Gastritis & 1 & - & - & 1 & - & 0.78 \\
\hline Migraine & 1 & - & - & 1 & - & 0.78 \\
\hline Ileus & 1 & - & - & 1 & - & 0.78 \\
\hline Infertility & 1 & - & - & 1 & - & 0.78 \\
\hline Sleep apnea & 1 & - & - & 1 & - & 0.78 \\
\hline Ankylosing spondylitis & - & 1 & - & 1 & - & 0.78 \\
\hline Cyst hydatic & - & 1 & - & 1 & - & 0.78 \\
\hline Coronary artery disease & - & 1 & - & 1 & - & 0.78 \\
\hline Multiple sclerosis & - & 1 & - & 1 & - & 0.78 \\
\hline Scoliosis & - & 1 & - & 1 & - & 0.78 \\
\hline Cerebrovascular disease & - & 1 & - & 1 & $1(100 \%)$ & $0.00025\left(^{*}\right)$ \\
\hline Morbid obesity (BMI $\geq 40$ ) & - & 1 & - & 1 & $1(100 \%)$ & $0.00025\left(^{*}\right)$ \\
\hline Thalassemia & - & 1 & - & 1 & $1(100 \%)$ & $0.00025\left(^{*}\right)$ \\
\hline Post bariatric & - & - & 1 & 1 & - & - \\
\hline $\begin{array}{l}\text { Total number of patients with } \\
\text { concomitant diseases }\end{array}$ & 47 & 27 & 4 & 78 & $8(10.2 \%)$ & \\
\hline $\begin{array}{l}\text { Total number of patients without } \\
\text { concomitant diseases }\end{array}$ & 52 & 28 & 28 & 108 & $5(4.6 \%)$ & 0.13 \\
\hline
\end{tabular}

Significant $p$-values are shown in bold.

BMI: Body mass index; $(*): p<0.05$

distance was $27 \mathrm{~cm}$ (range: $24-45 \mathrm{~cm}$ ) for the right breast and 26 $\mathrm{cm}$ (range: $24-45 \mathrm{~cm}$ ) for the left breast. The median postoperative SN-nipple distance was $20.5 \mathrm{~cm}$ (range: 18-23 cm) for both breasts (Table 1).

\section{Inferior pedicle}

The median total reduction weight, median right breast reduction weight, and median left breast reduction weight were 2,200 (range: 1,600-4,400) grams, 1,100 (range: $800-2,200$ ) grams, and 1,100 (range: $800-2,200)$ grams, respectively. The median preoperative SNnipple distance was $30 \mathrm{~cm}$ (range: $24-43 \mathrm{~cm}$ ) for the right breast and $30 \mathrm{~cm}$ (range: $24-43 \mathrm{~cm}$ ) for the left breast. The median postoperative SN-nipple distance was $20 \mathrm{~cm}$ (range: 18-22 cm) for both breasts (Table 1).

The overall complication rate was $6.9 \%$. A free nipple graft was needed during surgery for hematoma in three patients, infection occurred in one patient, enlarged scar formation in one patient, wound healing problems in two patients, development of areolar partial necrosis in two patients, and areolar total necrosis in one patient. The complication rates in patients with and without concomitant diseases were $10.2 \%$ and $4.6 \%$, respectively (Table 3 ). These results reveal 2.2 times increase in the risk of complication in patients with concomitant diseases. The overall complication rate was significantly higher in patients with smoking habit $(25 \%, \mathrm{p}=0.04)$, accessory breast $(50 \%$, $\mathrm{p}=0.01)$, progesterone use $(50 \%, \mathrm{p}=0.01)$, cerebrovascular disease $(100 \%, p=0.00025)$, morbid obesity $\left(\right.$ BMI $\geq 40 \mathrm{~kg} / \mathrm{m}^{2} ; 100 \%$, $\mathrm{p}=0.00025)$, and thalassemia $(100 \%, \mathrm{p}=0.00025)$. The overall complication rate was higher in patients with diabetes mellitus ( $9 \%$, $\mathrm{p}=0.77$ ), but this increase was not significant. In addition, no correlation was found between complications and high blood pressure, psychiatric conditions, asthma, hyperthyroidism, arrhythmia, gastritis, migraine, ileus, infertility, sleep apnea, ankylosing spondylitis, cyst hydatic, coronary artery disease, multiple sclerosis, scoliosis, and post bariatric surgery $(\mathrm{p}>0.05)$ (Table 2 , Figure 5$)$. The median total reduction amount in 13 patients with postoperative complications was 
2,600 (range: 462-4,800) grams; compared with the total reduction amount in patients without any complications, the difference was not significant $(\mathrm{p}=0.07)$. The median SN-nipple distance in 13 patients with postoperative complications was $35 \mathrm{~cm}$ (range: 24-45 $\mathrm{cm}$ ); compared with the SN-nipple distance in patients without any complications, the difference was not significant $(\mathrm{p}=0.06)$. The complication rates were $6.06 \%, 7.2 \%$, and $9.3 \%$ for the superomedial, superior, and inferior pedicles, respectively, and the difference was not significant $(\mathrm{p}>0.05)$. The risk for partial areolar necrosis was significantly increased in patients with superior pedicled breast reduction ( $\mathrm{p}=0.02$ ) compared with other pedicle techniques. The risk for nipple contraction/nipple sensory loss was significantly increased in patients with inferior pedicled breast reduction $(\mathrm{p}=0.02)$ compared with other pedicle techniques. No other significant correlation was found between a specific complication and pedicle type.

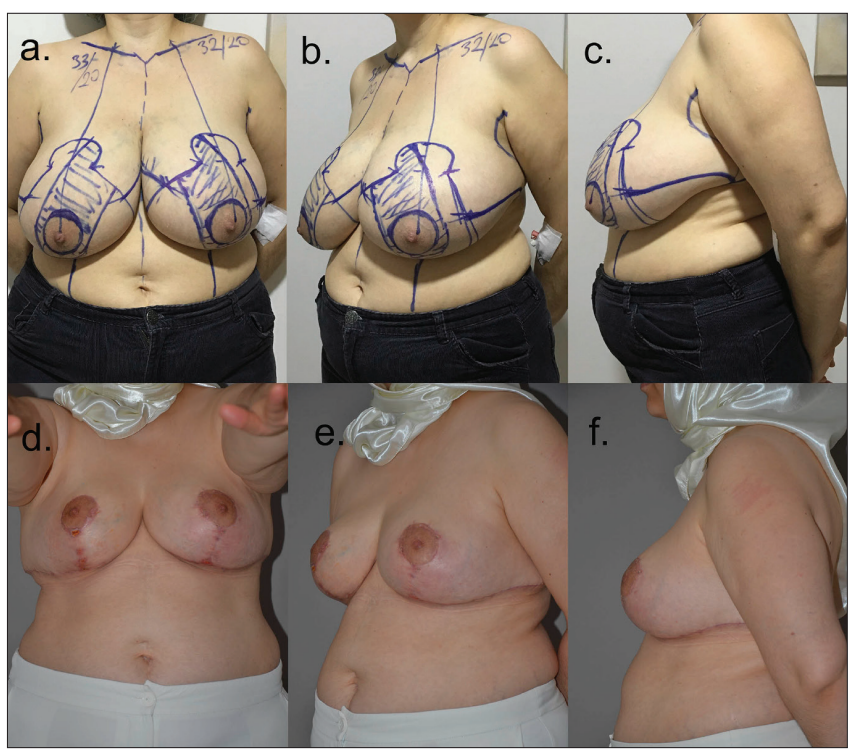

Figure 3. Preoperative frontal (a), oblique (b), and lateral (c) views of a patient. Two-month postoperative frontal (a), oblique (b), and lateral (c) views of the patient following breast reduction with the superomedial pedicle

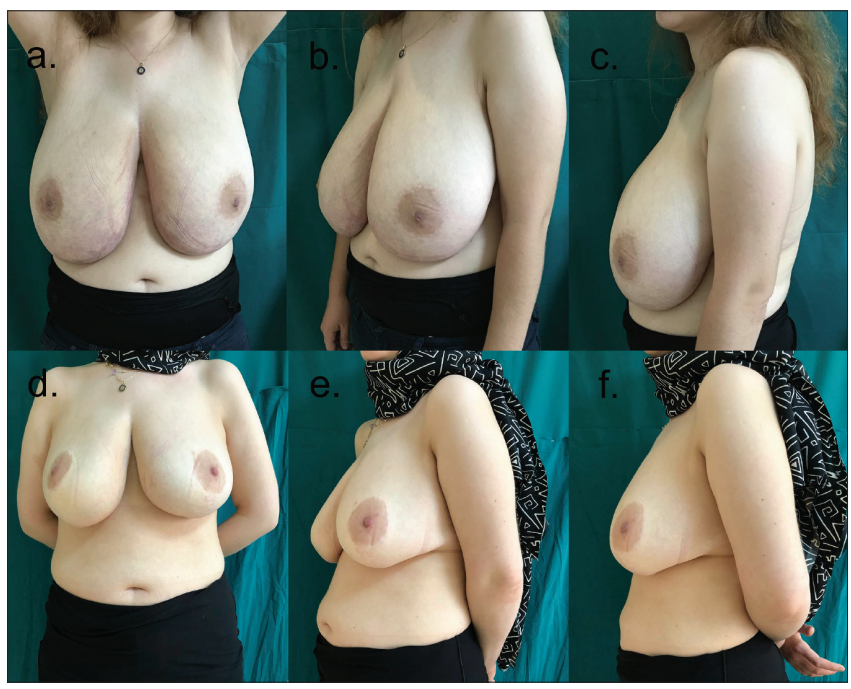

Figure 4. Preoperative frontal (a), oblique (b), and lateral (c) views of a patient. Five-year postoperative frontal (a), oblique (b), and lateral (c) views of the patient following breast reduction with the inferior pedicle
Complications were properly treated in the clinic by hematoma evacuation, antibiotic therapy, scar revision, necrosis debridement, secondary suturing, and dressing. All patients were followed up for an average of 4 years in terms of wound separation, scar pigmentation, areola and fat necrosis, sensory quality, hypertrophic scar, and keloid. As a result, satisfactory results were achieved in terms of aesthetic appearance over a long-term period. None of the patients had complaints regarding the shape of the breasts. All patients were doing well at the $6^{\text {th }}$ postoperative month, and all of them had gained symptomatic relief after surgery.

\section{Discussion and Conclusion}

Prior to breast reduction, surgeons would have chosen a skin incision pattern and a pedicle technique appropriate for the patient's needs. In our clinic, we use both vertical technique and inverted t skin pattern technique depending on the size of the breast, degree of sagging, and patient's wishes. Even in cases where we chose the inverted t technique, we were able to shorten the horizontal scar component, owing to our increasing experience of the vertical technique. That is, when a short transverse scar is added to the vertical technique, or when the traverse scar component in the inverted t technique is shortened, the difference between the vertical and inverted $t$ techniques becomes less obvious (1).

Most American plastic surgeons still use the inferior pedicle and inverted $\mathrm{t}$ scar pattern. This technique has many important advantages, as it is primarily reproducible, simple, and easy to teach. Skin incisions are largely compatible with glandular incisions in the breast parenchyma. In this way, after the preoperative drawings were made, all surgical progressive planning such as cutting of tissues and closing of the wound can be completed by following the line markings. This provides a great advantage in terms of predictability and reliability. In contrast, in vertical scar techniques, there is a marked discrepancy between skin incisions and glandular incisions under the skin. To obtain an acceptable result, the amount of tissue to be removed must be well adjusted and tissues must be reshaped during surgery. Finally, it may be necessary to adjust the excess skin

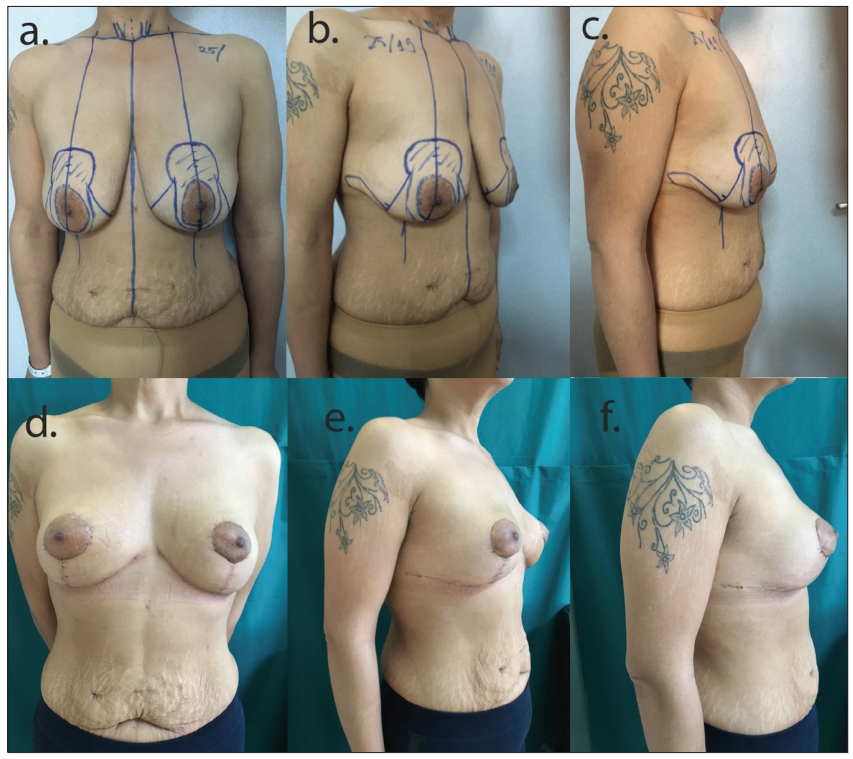

Figure 5. Preoperative frontal (a), oblique (b), and lateral (c) views of a patient. One-year postoperative frontal (a), oblique (b), and lateral (c) views of the patient following breast reduction with the superior pedicle 
Table 3. Complication rates following surgery

\begin{tabular}{|c|c|c|c|c|c|c|c|c|c|c|c|}
\hline & \multicolumn{2}{|c|}{$\begin{array}{l}\text { All patients } \\
\quad(n=186)\end{array}$} & \multicolumn{3}{|c|}{$\begin{array}{l}\text { Superomedial pedicle } \\
\qquad(\mathrm{n}=99)\end{array}$} & \multicolumn{3}{|c|}{ Superior pedicle $(n=55)$} & \multicolumn{3}{|c|}{ Inferior pedicle $(n=32)$} \\
\hline & $\begin{array}{l}\text { ๖̀ } \\
\text { है } \\
\text { ż }\end{array}$ & 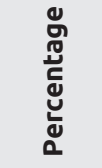 & $\begin{array}{l}\text { Łั } \\
\text { है } \\
\text { ż }\end{array}$ & 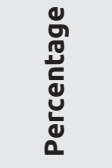 & 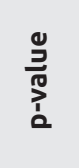 & $\begin{array}{l}\text { 호 } \\
\text { है } \\
\text { Z }\end{array}$ & 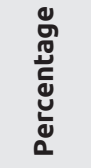 & 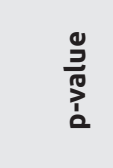 & $\begin{array}{l}\text { ๖े } \\
\text { है } \\
\text { Ż }\end{array}$ & 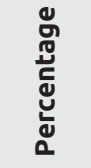 & 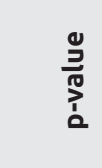 \\
\hline Overall complication rate & 13 & $6.9 \%$ & 6 & $6.06 \%$ & 0.59 & 4 & $7.2 \%$ & 0.92 & 3 & $9.3 \%$ & 0.56 \\
\hline $\begin{array}{l}\text { Hematoma followed by } \\
\text { free nipple graft }\end{array}$ & 3 & $1.6 \%$ & 2 & $2.02 \%$ & 0.63 & 1 & $1.8 \%$ & 0.88 & - & - & 0.42 \\
\hline Infection & 1 & $0.53 \%$ & 1 & $1.01 \%$ & 0.34 & - & - & 0.51 & - & - & 0.64 \\
\hline Hypertrophic scar & 1 & $0.53 \%$ & 1 & $1.01 \%$ & 0.34 & - & - & 0.51 & - & - & 0.64 \\
\hline Wound dehiscence & 2 & $1.07 \%$ & 1 & $1.01 \%$ & 0.92 & - & - & 0.35 & 1 & $3.1 \%$ & 0.21 \\
\hline Partial areolar necrosis & 2 & $1.07 \%$ & - & - & 0.12 & 2 & $3.6 \%$ & $0.02(*)$ & - & - & 0.51 \\
\hline Total areolar necrosis & 1 & $0.53 \%$ & - & - & 0.28 & - & - & 0.35 & 1 & $3.1 \%$ & 0.21 \\
\hline Fat necrosis & 2 & $1.07 \%$ & 1 & $1.01 \%$ & 0.92 & 1 & $1.8 \%$ & 0.52 & - & - & 0.51 \\
\hline $\begin{array}{l}\text { Nipple contraction/nipple } \\
\text { sensory loss }\end{array}$ & 1 & $0.53 \%$ & - & - & 0.28 & - & - & 0.51 & 1 & $3.1 \%$ & $0.02\left(^{*}\right)$ \\
\hline Revision surgery & 6 & $3.22 \%$ & 4 & $4.04 \%$ & 0.50 & 2 & $3.6 \%$ & 0.82 & - & - & 0.25 \\
\hline
\end{tabular}

remaining in the caudal part of the vertical incision when closing the skin (1).

Orlando and Guthrie were the first to describe and present the reliability of SMP techniques. As advantages, the SMP technique maintains the dermoglandular integrity of the NAC. The pedicle can be kept in full thickness and rotated without thinning. This reduces the risk of nipple necrosis, a frightening complication, not only due to the predominant perforator vessels of the internal thoracic artery, but also due to the microvascular connection of the dermal plexus. Other researchers argue that this helps improve the venous drainage of the NAC. Although not evaluated, the duration of surgery tends to be shorter with this technique because much less time is spent during surgery and breast shaping closure can be performed more easily and quickly than other techniques.

The complication rates in our study were lower than those in other published complication rates associated with SMP use (20). Four previous studies have compared the two techniques and provided individual complication rates (20-23). In 17 cases selected from 1987 to 2019 , complications related to the superomedial technique were discussed. The mean complication rate ranged from $16.9 \%$ to $43 \%$ (20). Twenty publications have discussed complications associated with the use of the inferior pedicle technique. The average complication rate ranged from $29.7 \%$ to $71 \%$ (20).

Our analysis shows that the adoption of less common techniques, such as superomedial reduction mammoplasties, is potentially safe as with the inferior pedicle technique, while providing additional benefits. Numerous studies have drawn attention to maintaining long superomedial fullness, lower tendency to pseudoptosis, and rapid
In previous studies, higher complication risks were found patients with high BMI, excessive tissue resection weight, and long SNnipple distance $(20,22,24,29)$. In other studies, the complication rate related to the patient's age and tobacco use did not increase $(25,30)$. Gulcelik et al. (31) reported no difference in the rate of complications in patients with and without breast cancer who underwent breast reduction surgery. They have also found that BMI was the only factor associated with the complication rate. In our study, the overall complication rate was significantly higher in patients with smoking habit, accessory breast, progesterone use, cerebrovascular disease, morbid obesity $\left(\right.$ BMI $\left.\geq 40 \mathrm{~kg} / \mathrm{m}^{2}\right)$, and thalassemia. In addition, no correlation was found between complication rates and high blood pressure, excessive breast reduction weights, long SN-NAC distance, and presence of other concomitant diseases (32).

This study has some limitations. The overall complication rate was low, so results might be different in studies with higher number of patients and complications. Since this was a retrospective study, no specific evaluation of the aesthetic appearance was performed. A prospective randomized study could potentially produce more reliable and comparable results in this regard.

In conclusion, our analysis does not suggest that these three techniques have superiority to each other in terms of pedicle safety. Moreover, no significant correlation was found between the overall complication rate and other risk factors. In most cases, we preferred superomedial and superior pedicle reductions. However, some points need to be examined in more detail in future studies. It will be valuable to compare superomedial fullness and aesthetic breast shape obtained in the early period with that in the late period of using other reduction techniques. In addition, nipple sensitivity and lactation should be 
demonstrated with objective calculations instead of subjective and theoretical criteria.

Ethics Committee Approval: Since this is a retrospective study there is no ethics committee approval for this study. Patient consents were obtained for the study.

Informed Consent: Informed consents were obtained from all patients prior to the surgery.

Peer-review: Externally peer-reviewed.

\section{Authorship Contributions}

Conception: G.T.; Design: G.T., D.A., M.S.; Supervision: G.T., D.A., M.S.; Materials: G.T.; Data Collection or Processing: G.T.; Analysis or Interpretation: D.A., M.S.; Literature Search: G.T.; Writing: D.A., M.S.

Conflict of Interest: The authors declare that they have no conflicts of interest to disclose.

Financial Disclosure: The authors declared that this study received no financial support.

\section{References}

1. Chung KC. Grabb and Smith's Plastic Surgery. $8^{\text {th }}$ ed. Philadelphia, United States: Wolters Kluwer Health; 2010. [CrossRef]

2. Blomqvist L, Eriksson A, Brandberg Y. Reduction mammaplasty provides long-term improvement in health status and quality of life. Plast Reconstr Surg 2000; 106: 991-997. (PMID: 11039369) [CrossRef]

3. Brown AP, Hill C, Khan K. Outcome of reduction mammaplasty-a patients' perspective. Br J Plast Surg 2000; 53: 584-587. (PMID: 11000075) [CrossRef]

4. Chao JD, Memmel HC, Redding JF, Egan L, Odom LC, Casas LA. Reduction mammaplasty is a functional operation, improving quality of life in symptomatic women: a prospective, single-center breast reduction outcome study. Plast Reconstr Surg 2002; 110: 1644-1652; discussion 53-4. (PMID: 12447043) [CrossRef]

5. Cherchel A, Azzam C, De Mey A. Breastfeeding after vertical reduction mammaplasty using a superior pedicle. J Plast Reconstr Aesthet Surg 2007; 60: 465-470. (PMID: 17399654) [CrossRef]

6. Dabbah A, Lehman JA Jr, Parker MG, Tantri D, Wagner DS. Reduction mammaplasty: an outcome analysis. Ann Plast Surg 1995; 35: 337-341. (PMID: 8585673) [CrossRef]

7. Eggert E, Schuss R, Edsander-Nord A. Clinical outcome, quality of life, patients' satisfaction, and aesthetic results, after reduction mammaplasty. Scand J Plast Reconstr Surg Hand Surg 2009; 43: 201-206. (PMID: 19688643) [CrossRef]

8. Miller BJ, Morris SF, Sigurdson LL, Bendor-Samuel RL, Brennan M, Davis G, et al. Prospective study of outcomes after reduction mammaplasty. Plast Reconstr Surg 2005; 115: 1025-1031; discussion 323. (PMID: 15793440) [CrossRef]

9. O'Blenes CA, Delbridge CL, Miller BJ, Pantelis A, Morris SF. Prospective study of outcomes after reduction mammaplasty: long-term follow-up. Plast Reconstr Surg 2006; 117: 351-358. (PMID: 16462312) [CrossRef]

10. Iwuagwu OC, Platt AJ, Stanley PW, Hart NB, Drew PJ. Does reduction mammaplasty improve lung function test in women with macromastia? Results of a randomized controlled trial. Plast Reconstr Surg 2006; 118: 1-6; discussion 7. (PMID: 16816661) [CrossRef]

11. Mello AA, Domingos NA, Miyazaki MC. Improvement in quality of life and self-esteem after breast reduction surgery. Aesthetic Plast Surg 2010; 34: 59-64. (PMID: 19768493) [CrossRef]
12. Romeo M, Cuccia G, Zirilli A, Weiler-Mithoff E, Stagno d'Alcontres F. Reduction mammaplasty and related impact on psychosexual function. J Plast Reconstr Aesthet Surg 2010; 63: 2112-2116. (PMID: 20207212) [CrossRef]

13. Saariniemi KM, Keranen UH, Salminen-Peltola PK, Kuokkanen HO. Reduction mammaplasty is effective treatment according to two quality of life instruments. A prospective randomised clinical trial. J Plast Reconstr Aesthet Surg 2008; 61: 1472-1478. (PMID: 17983882) [CrossRef]

14. Singh KA, Losken A. Additional benefits of reduction mammaplasty: a systematic review of the literature. Plast Reconstr Surg 2012; 129: 562570. (PMID: 22090252) [CrossRef]

15. Kerrigan CL, Slezak SS. Evidence-based medicine: reduction mammaplasty. Plast Reconstr Surg 2013; 132: 1670-1683. (PMID: 24281593) [CrossRef]

16. Borchgrevink $\mathrm{H}$, Aass $\mathrm{K}$, Eikeland O. [Plastic reconstructive surgery of the breast]. Tidsskr Nor Laegeforen 1983; 103: 1981-1985. (PMID: 6648938) [CrossRef].

17. Orlando JC, Guthrie RH Jr. The superomedial dermal pedicle for nipple transposition. Br J Plast Surg 1975; 28: 42-45. (PMID: 1125478) [CrossRef]

18. Finger RE, Vasquez B, Drew GS, Given KS. Superomedial pedicle technique of reduction mammaplasty. Plast Reconstr Surg 1989; 83: 471480. (PMID: 2919201) [CrossRef]

19. Hall-Findlay EJ. A simplified vertical reduction mammaplasty: shortening the learning curve. Plast Reconstr Surg 1999; 104: 748-759; discussion 60-3. (PMID: 10456528) [CrossRef]

20. Bauermeister AJ, Gill K, Zuriarrain A, Earle SA, Newman MI. "Reduction mammaplasty with superomedial pedicle technique: A literature review and retrospective analysis of 938 consecutive breast reductions". J Plast Reconstr Aesthet Surg 2019; 72: 410-418. (PMID: 30579911) [CrossRef]

21. Antony AK, Yegiyants SS, Danielson KK, Wisel S, Morris D, Dolezal RF, et al. A matched cohort study of superomedial pedicle vertical scar breast reduction (100 breasts) and traditional inferior pedicle Wise-pattern reduction (100 breasts): an outcomes study over 3 years. Plast Reconstr Surg 2013; 132: 1068-1076. (PMID: 24165588) [CrossRef]

22. Lugo LM, Prada M, Kohanzadeh S, Mesa JM, Long JN, de la Torre J. Surgical outcomes of gigantomastia breast reduction superomedial pedicle technique: a 12-year retrospective study. Ann Plast Surg 2013; 70: 533537. (PMID: 23542843) [CrossRef]

23. Serra MP, Longhi P, Sinha M. Breast reduction with a superomedial pedicle and a vertical scar (Hall-Findlay's technique): experience with 210 consecutive patients. Ann Plast Surg 2010; 64: 275-278. (PMID: 20179472) [CrossRef]

24. Brown RH, Siy R, Khan K, Izaddoost $S$. The superomedial pedicle wisepattern breast reduction: reproducible, reliable, and resilient. Semin Plast Surg 2015; 29: 94-101. (PMID: 26528085) [CrossRef]

25. Fischer JP, Cleveland EC, Shang EK, Nelson JA, Serletti JM. Complications following reduction mammaplasty: a review of 3538 cases from the 2005-2010 NSQIP data sets. Aesthet Surg J 2014; 34: 66-73. (PMID: 24334499) [CrossRef]

26. Kemaloglu CA, Ozocak H. Comparative outcomes of inferior pedicle and superomedial pedicle technique with wise pattern reduction in gigantomastic patients. Ann Plast Surg 2018; 80: 217-222. (PMID: 28984653) [CrossRef]

27. Makboul M, Abdelhamid M, Al-Attar G. Long term follow up and patient satisfaction after reduction mammoplasty: superomedial versus inferior pedicle. World J Plast Surg 2017; 6: 82-87. (PMID: 28289618) [CrossRef]

28. Nahabedian MY, McGibbon BM, Manson PN. Medial pedicle reduction mammaplasty for severe mammary hypertrophy. Plast Reconstr Surg 2000; 105: 896-904. (PMID: 10724248) [CrossRef] 
29. Hunter JG, Ceydeli A. Correlation between complication rate and tissue resection volume in inferior pedicle reduction mammaplasty: a retrospective study. Aesthet Surg J 2006; 26: 153-156. (PMID: 19338895) [CrossRef]

30. Henry SL, Crawford JL, Puckett CL. Risk factors and complications in reduction mammaplasty: novel associations and preoperative assessment. Plast Reconstr Surg 2009; 124: 1040-1046. (PMID: 19935287) [CrossRef]
31. Gulcelik MA, Dogan L, Camlibel M, Karaman N, Kuru B, Alagol H, et al. Early complications of a reduction mammoplasty technique in the treatment of macromastia with or without breast cancer. Clin Breast Cancer 2011; 11: 395-399. (PMID: 21993009) [CrossRef]

32. Ozcelik D, Unveren T, Toplu G, Bilgen F, Iskender A, Senyuva C. Vertical mammaplasty for gigantomastia. Aesthetic Plast Surg 2009; 33: 246-249. (PMID: 18953594) [CrossRef] 